\title{
Porcine pancreastatin has no effect on endocrine secretion from the pig pancreas
}

\author{
J.J.Holst ${ }^{1}$, C.-G. Östenson ${ }^{2}$, H. Harling ${ }^{1}$ and T.Messell ${ }^{1}$ \\ ${ }^{1}$ Institute of Medical Physiology C, The Panum Institute, University of Copenhagen, Copenhagen, Denmark, and \\ ${ }^{2}$ Department of Endocrinology, Karolinska Hospital, Stockholm, Sweden
}

Summary. We investigated the effects of porcine pancreastatin on the endocrine and unstimulated exocrine secretion of isolated, perfused porcine pancreas. Pancreastatin in a concentration of $10^{-8} \mathrm{~mol} / \mathrm{l}$ had no effect on basal secretion of insulin, glucagon and somatostatin at a perfusate glucose concentration of $5 \mathrm{mmol} / \mathrm{l}(n=4)$ and neither at $10^{-8}$ nor $10^{-7} \mathrm{~mol} / \mathrm{l}$ influenced the hormone responses to acute elevations of perfusate glucose concentration from 3.5 to
$11 \mathrm{mmol} / \mathrm{l}(n=7)$. This elevation strongly stimulated insulin secretion and inhibited glucagon secretion. Exocrine secretion was not affected by pancreastatin. The results suggest that pancreastatin does not directly influence pancreatic secretion.

Key words: Insulin, glucagon, somatostatin, pancreatic exocrine secretion, chromogranin A, perfused pancreas.
Pancreastatin is a 49 amino acid residue peptide that was isolated recently from the porcine pancreas [1]. It has been reported that pancreastatin inhibits, in isolated pancreas and islets of the rat, insulin release induced by glucose, arginine, sulfonylureas and phosphodiesterase inhibition (IBMX) [1-4]. Furthermore, the peptide has been shown to inhibit arginine-stimulated somatostatin release from the perfused rat pancreas [2] and enhance basal glucagon levels in mice in vivo [5]. Since the structure of porcine pancreastatin is identical with a sequence of porcine chromogranin A [6], it is likely that the latter molecule could serve as a precursor for pancreastatin. Pancreastatin-like immunoreactivity has been demonstrated together with insulin in the granules of the Beta cells and it was shown recently that insulin and pancreastatin are released in parallel upon stimulation [7]. Being itself a secreted product of the Beta cell it seems surprising that its physiological role is control of Beta cell secretion. One possibility is that it acts as a link in a negative feed-back loop. However, the amino acid sequence of pancreastatin, as it occurs in chromogranin A, seems to vary markedly between species [6]. Therefore, it could be of importance to investigate the effects of this peptide in the homologous species. We report here on the effects of porcine pancreastatin on the endocrine secretion of the porcine pancreas.

\section{Materials and methods}

\section{Isolated perfused porcine pancreas}

Thirteen pigs weighing $14-16 \mathrm{~kg}$ that were fasted overnight with free access to water, were anaesthetized without premedication with 2.5\% Halothane (Halocarbon Laboratories Inc., NJ, USA) in $\mathrm{N}_{2} \mathrm{O} / \mathrm{O}_{2}$ for induction, followed by i.v. infusion of chloralose (100 mg/kg, Merck, Darmstadt, FRG). Anaesthesia was maintained with chloralose and $\mathrm{N}_{2} \mathrm{O} / \mathrm{O}_{2}$. Isolation of the pancreas was performed as previously described [8]. The isolated pancreases were placed in a single pass perfusion system as previously described [9], and perfused at a rate of $0.5 \mathrm{ml} \cdot \mathrm{min}^{-1} \cdot \mathrm{g}^{-1}[10]$. The perfusion medium consisted of a Krebs-Ringer bicarbonate buffer, containing in addition: $0.1 \%$ human serum albumin ("Reinst, Trocken", Behringwerke, Marburg, FRG); 5\% dextran (Dextran T-70, Pharmacia, Uppsala, Sweden), glucose as specified below, 100,000 kallikrein-inhibitor units/iter of aprotinin (Trasylol, Bayer, Leverkusen, FRG), and a mixture of amino acids (Amodex Asa, Pharmacia) to a total concentration of $5 \mathrm{mmol} / \mathrm{l}$. In four perfusion experiments aprotinin and amino acids were omitted from the perfusate.

The venous effluent was collected for 1 -min periods in polyethylene tubes (Minisorp, Technunc, Roskilde, Denmark), chilled in ice, and kept at $-20^{\circ} \mathrm{C}$ until assayed for insulin, glucagon and somtostatin as described previously [9-11].

Pancreastatin for perfusion was synthesized and purified as previously described [2]. The peptide was dissolved in the albumin-containing perfusion medium before infusion. By radioimmunoassay [7] is was ascertained that the concentration of pancreastatin in the perfusion medium corresponded with the concentration that was expected to result from the infusion. 


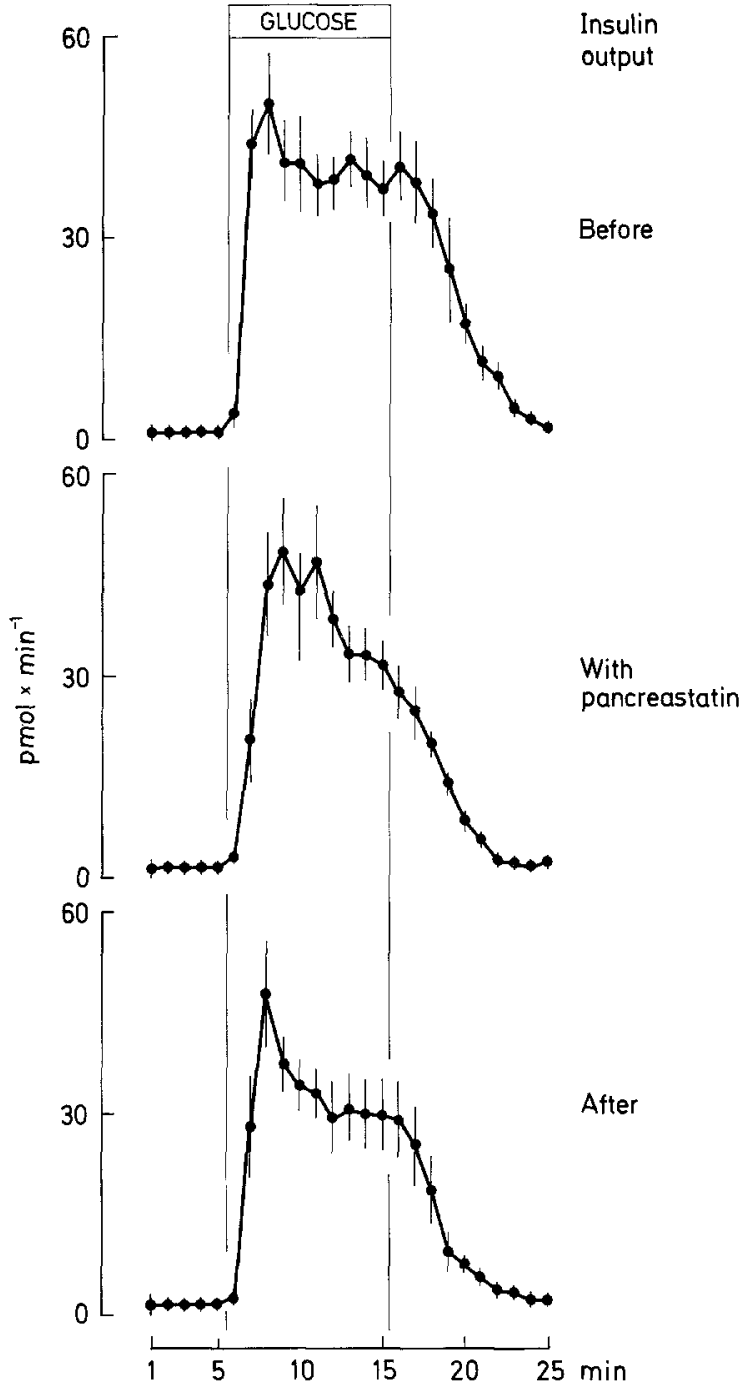

Fig. 1. Secretion of insulin from isolated perfused porcine pancreas in response to an elevation of the perfusate concentration of glucose from $3.5 \mathrm{mmol} / 1$ to $11 \mathrm{mmol} / \mathrm{l}$ before, during and after addition of pancreastatin to the perfusate to a concentration of $10^{-8} \mathrm{~mol} / \mathrm{l}$. Mean $\pm \operatorname{SEM}(n=7)$

In four perfusion experiments the perfusate glucose concentration was kept constant at $5 \mathrm{mmol} / 1$, and pancreastatin infused via a side arm to reach a final concentration of $10^{-8} \mathrm{~mol} / \mathrm{l}$ perfusion medium for $10 \mathrm{~min}$. In seven perfusion experiments the glucose concentration in the perfusion medium was kept at $3.5 \mathrm{mmol} / \mathrm{l}$. In these experiments square-wave increases in glucose concentration up to $11 \mathrm{mmol} / \mathrm{l}$ were produced by infusion of additional glucose by means of a precision pump attached to a side arm of the perfusion line. Five min before the glucose increase, pancreastatin was added to the perfusate to reach $10^{-8} \mathrm{~mol} / \mathrm{l}$. The pancreastatin infusion was continued until the termination of the glucose infusion. A control infusion of glucose without pancreastatin was performed $25 \mathrm{~min}$ before as well as $25 \mathrm{~min}$ after the pancreastatin infusion. In three experiments the same protocol was followed, but this time pancreastatin was infused to reach a concentration of $10^{-7} \mathrm{~mol} / \mathrm{l}$ and the pancreastatin infusion was started $10 \mathrm{~min}$ before the glucose infusions. In five perfusion experiments $11 \mathrm{mmol} / \mathrm{l}$ square wave glucose stimulations as above were performed twice with an interval of $25 \mathrm{~min}$ but without infusion of pancreastatin. Pancreatic exocrine secretion was collected for 10 min periods throughout all experiments and analysed for volume, protein and bicarbonate concentration as previously described [8].
Statistical analysis

The results are presented as mean $\pm S E M$. Hormone outputs were calculated by multiplication of perfusion flow rate and hormone concentration in the effluent. For statistical analysis the hormone outputs were compared by analysis of variance (ANOVA) or $t$-test for pair data as appropriate. The level of statistical significance was chosen as $p<0.05$.

\section{Results}

The pancreastatin infusions had no effect at all on the basal secretion of insulin, glucagon and somatostatin at a perfusate glucose concentration of $5 \mathrm{mmol} / \mathrm{l}$ (not shown).

Figure 1 shows the insulin secretion in response to an acute elevation of the perfusate glucose concentration from 3.5 to $11 \mathrm{mmol} / \mathrm{l}$. In all experiments insulin secretion increased markedly. Before pancreastatin (at $10^{-8} \mathrm{~mol} / \mathrm{l}$ ) the stimulated insulin output was $381 \pm 37 \mathrm{pmol} / 10 \mathrm{~min}$. With pancreastatin the output was $341 \pm 36 \mathrm{pmol} / 10 \mathrm{~min}$, and after pancreastatin $302 \pm 37 \mathrm{pmol} / 10 \mathrm{~min}$. By analysis of variance there was no statistical difference between the three insulin outputs.

Figure 2 shows the glucagon secretion in the same experiments. Before, as well as during and after pancreastatin, the glucose infusion strongly suppressed glucagon secretion. The glucagon outputs were $17.4 \pm 4.6 \mathrm{pmol} /$ $10 \mathrm{~min} ; 13.4 \pm 2.8$; and $12.3 \pm 5.1 \mathrm{pmol} / 10 \mathrm{~min}$, respectively. Pancreastatin had no discernible effect on the glucagon output. Similarly, pancreastatin had no effect on the inhibitory effect of glucose calculated as the integrated decrease in glucagon output expressed in per cent of basal secretion.

Figure 3 shows the somatostatin secretion. There was no significant effect of glucose on the somatostatin secretion (by analysis of all of the glucose stimulation experiments $(n=18)$ ), and there was no effect of pancreastatin on the somatostatin outputs obtained during the glucose infusions $(62 \pm 14 \mathrm{pmol} / 10 \mathrm{~min}$ before; $74 \pm 21 \mathrm{pmol} /$ $10 \mathrm{~min}$ during; and $108 \pm 27 \mathrm{pmol} / 10 \mathrm{~min}$ after the pancreastatin infusion. There was a slight but significant increase in the rate of secretion of somatostatin as a function of time.

Three of the perfusion experiments shown in Figures 1-3 were performed without aprotinin and amino acids present in the perfusate, but the results were similar to the remaining results, and all results were therefore combined.

In three perfusion experiments we made similar repeated elevations of the perfusate glucose concentration from 3.5 to $11 \mathrm{mmol} / \mathrm{l}$, but this time pancreastatin was infused to reach a final concentration of $10^{-7} \mathrm{~mol} / \mathrm{l}$ and the infusion was started $10 \mathrm{~min}$ before the second glucose infusion. Before pancreastatin infusion the mean glucosestimulated insulin output was $334 \pm 96 \mathrm{pmol} / 10 \mathrm{~min}$. With pancreastatin the mean output was $369 \pm 53 \mathrm{pmol} / 10 \mathrm{~min}$. The inhibitory effect of glucose on glucagon secretion, calculated as the integrated decrease below the basal level was $-34.0 \pm 10.7 \mathrm{pmol} / 10 \mathrm{~min}$ before pancreastatin and $37.3 \pm 12 \mathrm{pmol} / 10 \mathrm{~min}$ with pancreastatin. Somatostatin secretion did not change during glucose infusion. There 


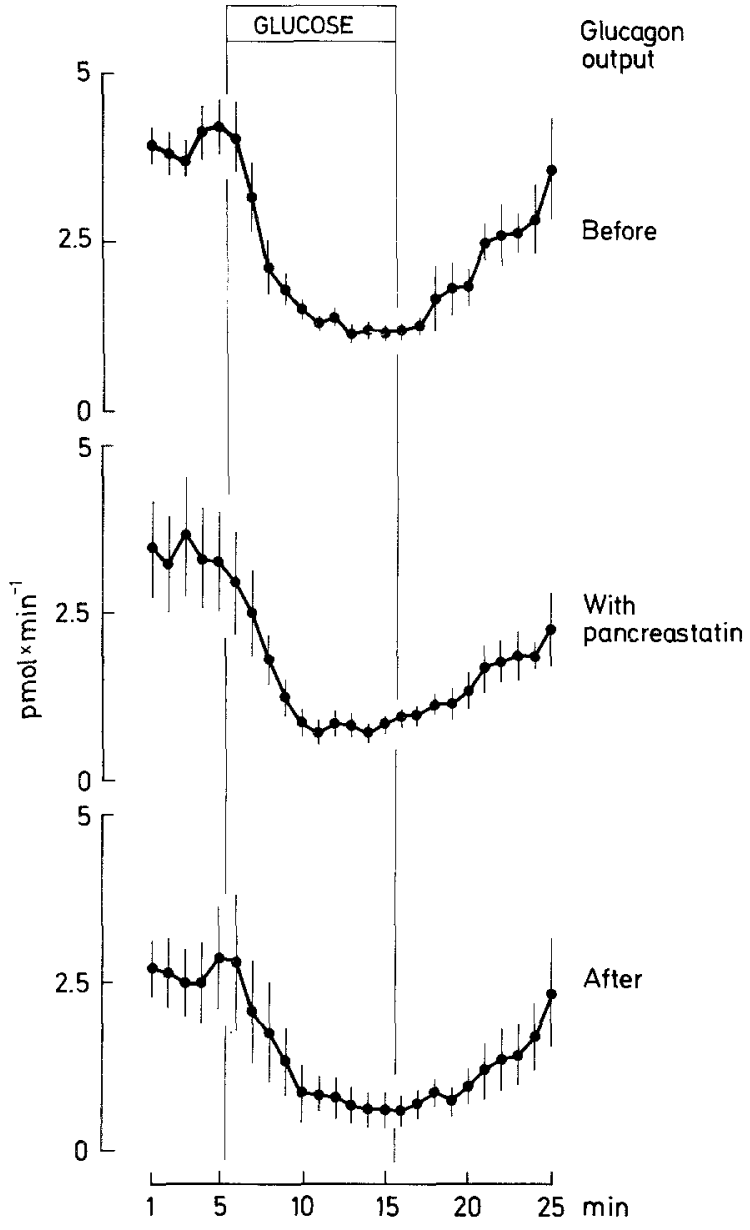

Fig. 2. Secretion of glucagon from isolated perfused pancreas in response to an elevation of the perfusate concentration of glucose from $3.5 \mathrm{mmol} / \mathrm{l}$ to $11 \mathrm{mmol} / \mathrm{l}$ before, during and after addition of pancreastatin to the perfusate to a concentration of $10^{-8} \mathrm{~mol} / \mathrm{l}$. Mean $\pm \operatorname{SEM}(n=7)$

were no significant differences between the results obtained with and without pancreastatin for any hormone.

In the five control experiments with repeated glucose stimulation but no infusion of pancreastatin the total insulin output during the first $10 \mathrm{~min}$ glucose stimulation was $305 \pm 35 \mathrm{pmol} / 10 \mathrm{~min}$ and $323 \pm 56 \mathrm{pmol} / 10 \mathrm{~min}$ during the second stimulation. This difference was not statistically significant.

There was no effect of pancreastatin on the exocrine secretion of the pancreas. The unstimulated basal secretion was $1.0 \pm 0.2 \mathrm{ml} / \mathrm{h}$, the basal protein output $24 \pm 6 \mathrm{mg} / \mathrm{h}$ and the bicarbonate output $0.09 \pm 0.01 \mathrm{mmol} / \mathrm{h}$. The rate of secretion did not change during glucose infusions.

\section{Discussion}

In this study we were unable to find any effect whatsoever of pancreastatin on pancreatic exocrine secretion. Pancreastatin neither inhibited the basal exocrine secretion nor had any stimulatory activity of its own. These results

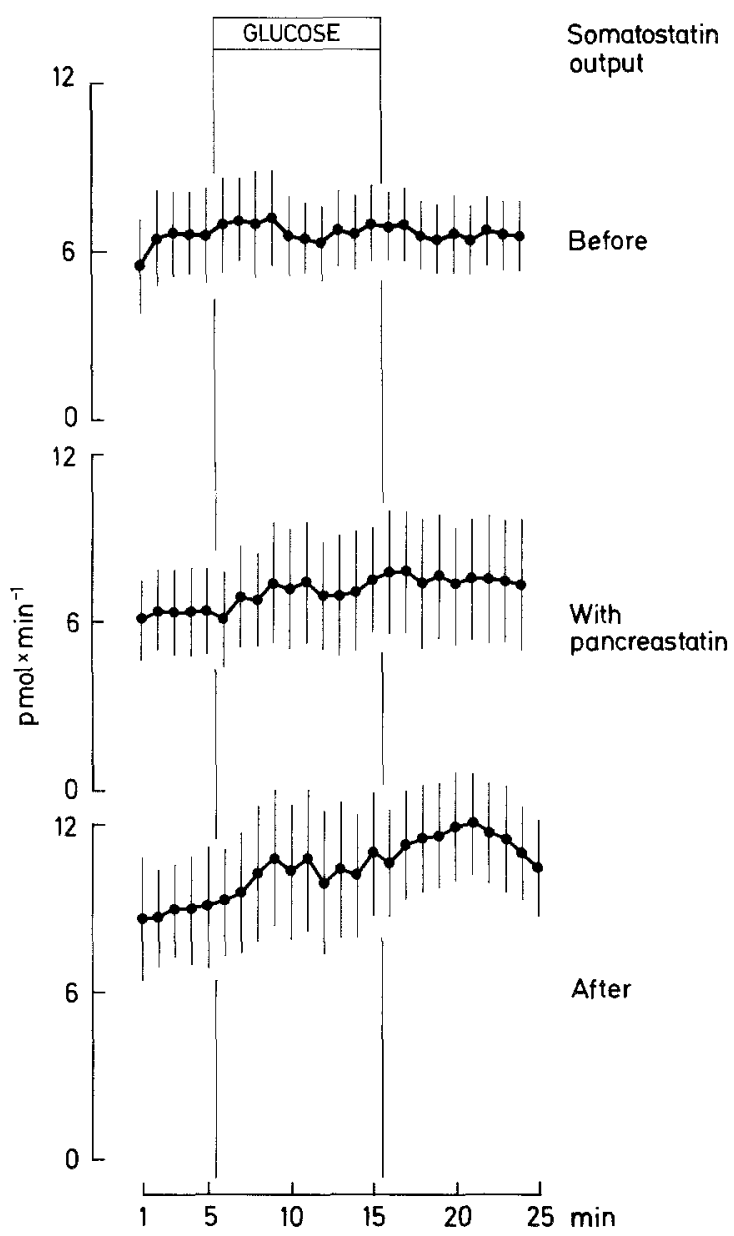

Fig. 3. Secretion of somatostatin from isolated perfused pancreas in response to elevations of the perfusate glucose concentration from $3.5 \mathrm{mmol} / \mathrm{l}$ to $11 \mathrm{mmol} / \mathrm{l}$ before, during, and after the addition to the perfusate of pancreastatin to a concentration of $10^{-8} \mathrm{~mol} / \mathrm{l}$. Mean $\pm \operatorname{SEM}(n=7)$

do not exclude, of course, that pancreastatin could inhibit stimulated exocrine secretion.

Pancreastatin had no effect at all on the endocrine secretion of insulin, glucagon and somatostatin at a glucose concentration in the perfusate corresponding to euglycaemia in pigs. We therefore also studied glucose-stimulated secretion, since this was the stimulus originally employed when the inhibitory activity of the peptide was discovered. Glucose infusions in all pancreases had the expected effect, i.e. a marked increase in insulin output, an inhibition of glucagon secretion and no effect on somatostatin secretion. In dogs and rats glucose may stimulate pancreatic somatostatin secretion [12], but in man and pigs infusion of glucose has little or no effect on pancreatic somatostatin secretion $[13,14]$. In order to avoid overlooking an existing effect we employed a double set of controls: the secretory responses to glucose plus pancreastatin were compared 1) to glucose-induced responses in the same perfusion experiment both before and after the pancreastatin experiment, and b) to the responses to repeated glucose infusions in control perfusion experiments in which pancreastatin was not given at all. Thus, we employed both internal and external controls. 
The insulin responses to repeated glucose stimulation with or without pancreastatin were statistically indistinguishable whether studied in the same pancreas or by comparison to control pancreases. Similarly, pancreastatin had no discernible influence on the glucagon and somatostatin responses to glucose.

The pancreastatin infusions were started $5\left(10^{-8} \mathrm{~mol} / \mathrm{l}\right.$ infusion) or $10 \mathrm{~min}\left(10^{-7} \mathrm{~mol} / 1\right.$ infusion $)$ before the glucose infusion to make sure that any receptor involved would be saturated or activated before the glucose infusion. The lower concentration of pancreastatin studied, $10^{-8} \mathrm{~mol} / \mathrm{l}$, is the same as that employed for the rat pancreas studies [2]. However, the 10-fold higher concentration was equally ineffective.

In our perfused organ preparation we routinely add amino acids and aprotinin to the perfusate, the former because many gastrointestinal organs combust amino acids, the latter to avoid accidental proteolysis. However, the omission or inclusion of these substances appeared to have no effect on the secretory results.

In rat islet Beta cells glucose-induced insulin secretion is enhanced by a preceeding glucose stimulus [15]. However, in our experiments there was no significant enhancement of the second insulin response. Thus, an inhibitory effect of pancreastatin on this so-called "glucose memory" could not be substantiated. In the rat pancreas the enhancing effect of glucose is usually demonstrated using $20-30 \mathrm{~min}$ pulses of $27.7 \mathrm{mmol} / 1$ glucose [15]. The difference in glucose loading may explain our inability to demonstrate the enhancing effect in the pig pancreas.

Our results do not support the concept that pancreastatin is involved in a local control of insulin secretion. Pancreastatin has been reported to inhibit insulin secretion in intact mice [5], and although that mechanism has not been worked out, it remains possible that porcine pancreastatin, infused into pigs may inhibit insulin secretion, e.g. by an effect on nervous pathways, similar to that observed for the somatostatin and glucagon induced inhibition of pancreatic exocrine secretion [16]. However, our findings do raise the question if the functions of pancreastatin should possibly be sought in entirely different directions. One effect of chromogranin A, the precursor of pancreastatin [6], has been reported to be the control of free $\mathrm{Ca}^{++}$concentration within the granules of the endocrine cells [17]. It remains possible that the true actions of pancreastatin are displayed during the course of the biosynthesis of the hormones.

Acknowledgements. Synthetic porcine pancreastatin was generously supplied by Dr. K. Tatemoto, Nancy Pritzker Lab., Stanford University School of Medicine, California, USA. The study was supported by grants (to C-G.Ö) from the Swedish Medical Research Council (19X-00034), Swedish Diabetes Association, Nordic Insulin Foundation, Magnus Bervall Foundation, Tore Nilson Foundation, and Swedish Hoechst Diabetes Foundation. JJH was supported by the Danish Biotechnology programme and the Danish Medical Research Council.

\section{References}

1. Tatemoto K, Efendic S, Mutt V, Makk G, Feistner GJ, Barchas JD (1986) Pancreastatin, a novel pancreatic peptide that inhibits insulin secretion. Nature 324: 476-478

2. Efendic S, Tatemoto K, Mutt V, Quan C, Chang D, Östenson C.Ö (1987) Pancreastatin and islet hormone release. Proc Nat1 Acad Sci USA 84: 7257-7260

3. Silvestre RA, Peiro E, Miralles P, Villanueva ML, Marco J (1988) Effects of pancreastatin on insulin, glucagon and somatostatin secretion by the perfused rat pancreas. Life Sci 42: 1361-1364

4. Ahrén B, Lindskog S, Tatemoto K, Efendic S (1988) Pancreastatin inhibits insulin secretion and stimulates glucagon secretion in mice. Diabetes 37: 281-285

5. Östenson C-G, Sandler S, Efendic S (1989) Effects of porcine pancreastatin on secretion and biosynthesis of insulin and glucose oxidation of isolated rat pancreatic islets. Pancreas 4: $441-446$

6. Iacangelo AL, Fischer-Colbrie R, Koller KJ, Brownstein MJ, Eiden LE (1988) The sequence of porcine chromogranin A messenger RNA demonstrates chromogranin A can serve as the precursor for the biologically active hormone, pancreastatin. Endocrinology 122: 2339-2341

7. Östenson C-G, Efendic S, Holst JJ (1989) Pancreastatin-like immunoreactivity and insulin are released in parallel from the perfused porcine pancreas. Endocrinology 124: 2986-2990

8. Lindkær-Jensen S, Kühl C, Holst JJ, Nielsen OV (1976) Isolation and perfusion of the porcine pancreas. A functional study. Scand J Gastroenterol [Suppl] 37: 57-61

9. Jensen SL, Fahrenkrug J, Holst JJ, Kühl C, Nielsen OV, Schaffalitzky de Muckadell OB (1978) Secretory effects of secretin on isolated perfused pancreas. Am J Physiol 235: E381-E 386

10. Holst JJ, Lindkær Jensen S, Schwartz TW (1980) Oxygen supply, oxygen consumption and endocrine and exocrine secretions of the isolated perfused porcine pancreas. Acta Physiol Scand 109: 7-13

11. Holst JJ, von Schenk H, Lindkær SL (1979) Gel filtration pattern of immunoreactive glucagon secreted by the isolated, perfused, porcine pancreas. Scand J Clin Lab Invest 39: 47-52

12. Hermansen K (1980) Secretion of somatostatin from the normal and diabetic pancreas. Studies in vitro. Diabetologia 19: 492-504

13. Grill V, Gutniak M, Roovete A, Efendic S (1984) A stimulating effect of glucose on somatostatin release is impaired in noninsulin-dependent diabetes mellitus. J Clin Endocrinol Metab 59: 293-297

14. Gustavsson S, Johansson H, Lundqvist G (1980) Pancreatic hormonal release after glucose and arginine administration in pigs. Acta Endocrinol (Kbh.) 93: 479-474

15. Grill V, Adamson U, Cerasi E (1978) Immediate and time-dependent effects of glucose on insulin release from rat pancreatic tissue. J Clin Invest 78: 1034-1043

16. Holst JJ (1987) Does the endocrine secretion of the pancreas exert a local control of the exocrine secretion? Pancreas 2: 613619

17. Reiffen FU, Gratzl M (1986) $\mathrm{Ca}^{++}$binding to chromaffin vesicle matrix proteins: effect of $\mathrm{pH}, \mathrm{Mg}^{*+}$, and ionic strength. Biochemistry 25:4402-4406

Received: 18 January 1990

and in revised form: 5 March 1990

Dr. J.J.Holst

Institute of Medical Physiology C

The Panum Institute

Blegdamsvej 3

DK-2200 Copenhagen N

Denmark 